Pacific Journal of Mathematics

ON GROUPS OF EXPONENT FOUR SATISFYING AN ANGEL

B. QUINTAN AND CHAR 


\title{
ON GROUPS OF EXPONENT FOUR SATISFYING AN ENGEL CONDITION
}

\author{
R. B. Quintana, JR. AND C. R. B. WRight
}

Let $B(n)$ be the Burnside (i.e., freest) group of exponent 4 on $n$ generators. It is known that $B(n)$ is nilpotent of class at most $3 n-1$. This paper exhibits a commutator of length $3 n-1$ in $B(n)$ which must be nontrivial if the class is exactly $3 n-1$. The methods also yield an easy proof of the following.

Theorem. Let $E(n)$ be $B(n)$ reduced modulo the identical commutator relation

$$
\left(a_{1}, \cdots, a_{2 n-4}, x, x,(y, z, z, z)\right)=1 .
$$

Then $E(n)$ is nilpotent of class at most $2 n+3$.

As an immediate corollary, every $n$-generator group of exponent 4 satisfying the Engel condition $(x, y, y, y)=1$ identically is of class at most $2 n+3$.

The theorem follows from Proposition 1 together with an elementary commutator calculation. The main point of the Proposition, however, is that it exhibits the stumbling block to a reduction in the class of $B(n)$ below $3 n-1$ and at the same time suggests that perhaps if for some $n$ the class is less than $3 n-1$ then the class in general is at most $2 n+k$ for some fixed $k$. Recent work of Gupta and others ([1], [2], [3]) has renewed interest in precise determination of the class and also in groups of exponent 4 satisfying Engel conditions. This paper updates the techniques of [4] as they appear to apply to these problems.

Preliminaries. This paper may be viewed as a continuation of [4]. Notation is the same, and for $i=1, \cdots, 9, A$ we denote formula (i) of [4] by (i) here, too. The symbol (i) in the margin at the right of an equation or congruence indicates that identity (i) justifies it. The notation $\langle x, \cdots, y\rangle$ stands for the group genarated by $\{x, \cdots, y\}$.

LEMma. The following commutator identities hold in a group of exponent 4.

(B). $(x,(u, v, w)) \equiv(x, u, w, v),(x, v, w, u) \bmod \langle x, u, w, v\rangle_{5}$.

(C). $(x, y, y, z, z, z) \equiv 1 \bmod \langle x, y, z\rangle_{\tau}$.

(D). $(x, y, y, y,(z, w)) \equiv 1 \bmod \langle x, y, z, w\rangle_{7}$.

Proof. Since 


$$
\begin{aligned}
& (x,(u, v, w)) \\
& \equiv(x,(u, v), w)(x, w,(u, v)) \\
& \equiv(x, u, v, w)(x, v, u, w)(x, u,(v, w))(x, v,(u, w)) \\
& \equiv(x, u, w, v)(x, v, w, u)
\end{aligned}
$$

(B) holds.

Since

$$
(x, y, y, z, z, z) \equiv(x, y, y, z)^{2} \equiv\left((x, y, y)^{2}, z\right) \equiv 1
$$

by (2) and Theorem 2 of [4], (C) holds.

Finally, since

$$
\begin{aligned}
(z, w,(x, y, y, y)) \equiv & (z, w,(x, y), y, y)(z, w, y, y,(x, y)) \\
\equiv & (z, w, x, y, y, y)(z, w, y, x, y, y) \\
& \times(z, w, y, y, x, y)(z, w, y, y, y, x) \equiv 1
\end{aligned}
$$

by (7) and (8), (D) holds.

Lemma. Let $G$ be a group of exponent 4 with $G_{r+1}=1$, and let $a$ and $x$ be in $G$. Then every commutator in $G$ of length $r$ of form

$$
(\cdots, x, x, a, x)
$$

is a product of commutators of forms

$$
(a, \cdots, x, x, x)
$$

and

$$
(a, \cdots, x, x, b, x)
$$

each with the same entries as the given commutator.

Proof. By induction on $r$. Since $(x, x, a, x)=1$, and

$$
\begin{aligned}
(b, x, x, a, x) & \equiv\left(b, x^{2}, a, x\right) \\
& \equiv\left(a, x^{2}, b, x\right)\left(a, b, x^{2}, x\right) \\
& \equiv(a, x, x, b, x)(a, b, x, x, x),
\end{aligned}
$$

the result is true for $r \leqq 5$. Now by (B),

$$
\begin{aligned}
(c, \ldots, d, e, x, x, a, x) \equiv & \left(c, \ldots, d, e, x^{2}, a, x\right) \\
\equiv & \left(c, \ldots, d, a, x^{2}, e, x\right)\left(c, \ldots, d,\left(a, e, x^{2}\right), x\right) \\
\equiv & \left(c, \ldots, d, a, x^{2}, e, x\right)(c, \ldots, d,(a, e), x, x, x) \\
& \times(c, \ldots, d, x, x,(a, e), x) .
\end{aligned}
$$

The first two factors are products of commutators of the required forms by (A). The last factor is a product of commutators of forms 


$$
(a, e, \ldots, x, x, x)
$$

and

$$
(a, e, \ldots, x, x, b, x)
$$

by the inductive assumption.

A consequence of this result is that Lemma 2 of [4] can be strengthened by the additional conclusion that $y_{1}=x_{1}$, i.e., that the first entry in $\left(x_{1}, \ldots, x_{n}\right)$ can be held fixed. It is clear from the proof of Lemma 2 that each commutator which arises has $x_{1}, \ldots, x_{n}$ in some order as its entries.

The main results.

Proposition 1. Let $G$ be a group of exponent 4 , and let $r \geqq 3 n \geqq 6$. Modulo $G_{r+1}$, every commutator $\left(a_{1}, \ldots, a_{r}\right)$ in which some $n$ entries each appear three or more times is a product of commutators of form

$$
\left(a, b, \ldots, x_{1}, x_{1}, x_{2}, x_{2}, \ldots, x_{n-1}, x_{n-1}, c, x_{n-1}, \ldots, x_{1}\right)
$$

with entries some permutation of $a_{1}, \ldots, a_{r}$.

Proof. We may assume that $G_{r+1}=1$, that $r>3 n$, by Theorem 3 of [4], and that no entry in $\left(a_{1}, \ldots, a_{r}\right)$ occurs more than three times, by Theorem 1 of [4]. Say each of $x_{1}, \ldots, x_{n}$ appears three times among $a_{1}, \ldots, a_{r}$. Since $r>3_{n}$, we may suppose that $a_{1}=$ $a \notin\left\{x_{1}, \ldots, x_{n}\right\}$, by (A) of [4]. Since $n \geqq 2$, some $x_{i}$ (say $x_{1}$ ) appears three times among $a_{3}, \ldots, a_{r}$. By Lemma 2 of [4] as just strengthened, we need only consider the forms

$$
\left(a, \ldots, x_{1}, x_{1}, x_{1}\right)
$$

and

$$
\left(a, \ldots, x_{1}, x_{1}, b, x_{1}\right)
$$

Case (I). By (7), (I) is equivalent to

$$
\left(a, b, x_{1}, x_{1}, x_{1}, \ldots\right)
$$

At least two of the last $r-5$ entries here are the same, say $x_{2}$, since $n \geqq 2$ and $a \neq x_{2}$. By repeated use of (D) and (3) these entries can be brought forward to give

$$
\left(a, b, x_{1}, x_{1}, x_{1}, x_{2}, x_{2}, \ldots\right) \text {. }
$$

By (7), $(a, b, x, x, x, y, y) \equiv(a, b, y, y, x, x, x$,$) , and now (C) applies.$ So $\left(a_{1}, \ldots, a_{r}\right)$ is trivial in this case.

Case (II). We have 


$$
\begin{aligned}
& \left(a, c, \ldots, x_{1}, x_{1}, b, x_{1}\right) \\
& =\left(a, c, x_{1}, x_{1}, d, x_{1}, \ldots, b\right) \\
& =\left(a, c, x_{1}, d, x_{1}^{2}, \ldots, b\right) \\
& \equiv\left(a, c,\left(x_{1}, d\right), x_{1}^{2}, \ldots, b\right)\left(a, c, d, x_{1}, x_{1}, x_{1}, \ldots, b\right) \\
& =\left(a, x_{1}^{2},\left(x_{1}, c\right), d, \ldots, b\right) \\
& =\left(a, x_{1}^{2}, c, x_{1}, d, \ldots, b\right)\left(a, x_{1}, x_{1}, x_{1}, c, d, \ldots, b\right) \\
& =\left(a, x_{1}^{2}, c, x_{1}, d, \ldots, b\right)
\end{aligned}
$$

the last step by the argument of Case (I).

Suppose inductively that we have reached the form

$$
\left(a, x_{1}^{2}, \ldots, x_{i}^{2}, c, x_{i}, \ldots, x_{1}, \ldots\right)
$$

with $1 \leqq i<n$. Some three of the last $r-3 i-2$ entries are the same, say $x_{i+2}$, and the argument just given yields the form

$$
\left(a, x_{1}^{2}, \ldots, x_{i}^{2}, x_{i+1}^{2}, c, x_{i+1}, x_{i}, \ldots, x_{1}, \ldots\right),
$$

where the improved Lemma 2 is used to keep the starting block of length $3 i-2$ at the front. The proposition follows by finite induction, using (9).

Together with (D), Proposition 1 shows in particular that $B(n)_{3 n-1}=1$ precisely if all commutators of form

$$
\left(a^{2}, x_{1}^{2}, x_{2}^{2}, x_{3}^{2}, \ldots, x_{n-1}^{2}, x_{1}, x_{n-1}, \ldots, x_{3}, x_{2}\right)
$$

are trivial.

Proposition 2. Let $G$ be a group of exponent 4 . Let $m \geqq 9$. If every commutator of length $m-1$ in $G$ of form

$$
(. ., x, x,(w, y, y, y))
$$

is in $G_{m+1}$, then every commutator of length $m$ in $G$ of form

$$
(\ldots, x, x, y, y, z, y, x)
$$

is in $\boldsymbol{G}_{m+1}$.

Proof. We may assume that $G_{m+1}=1$. Now for $a \in G_{m-7}$

$$
\begin{aligned}
&(a, x, x, y, y, z, y, x) \\
&=(a, x, x, z, y, y, x, y) \\
&=\left(a, x, x, z, y^{2},(x, y)\right)(a, x, x, z, y, y, y, x) \\
&=\left(a, x, x,(x, y), y^{2}, z\right)\left(a, x, x,\left(x, y, z, y^{2}\right)\right) \\
& \times(a, x, x, y, y, y, z, x)
\end{aligned}
$$




$$
\begin{aligned}
= & (a, x, x, x, y, y, y, z)(a, x, x, y, x, y, y, z) \\
& \times\left(a, x, x,\left(x, y, z, y^{2}\right)\right. \\
= & (a, x, x, x, y, z, y, y)\left(a, x, x,\left(x, y, z, y^{2}\right)\right) \\
= & \left(a, x, x,\left(y, x, z, y^{2}\right)\right) \\
= & \left(a, x, x,\left(y, x, y^{2}\right)\left(y, z, y^{2}\right)\left(y, x z, y^{2}\right)\right)=1
\end{aligned}
$$

by hypothesis.

Now let $n \geqq 3$ and let $E(n)$ be $B(n)$ reduced modulo the identical relation

$$
\left(a_{1}, \ldots, a_{2 n-4}, x, x,(y, z, z, z)\right)=1 .
$$

By Proposition 2 with $m=2 n+3$, every commutator of length $2 n+3$ in $E(n)$ of form $(\ldots, x, x, y, y, z, y, x)$ is in $E(n)_{2 n+4}$. Hence, by Proposition 1, every commutator of length $2_{n+4}$ in $E(n)$ in which three or more entries each appear three times is in $E(n)_{2 n+4}$. Finally, by Theorem 1 of [4], every commutator of length $2 n+3$ in $E(n)$ in which some entry appears four or more times is in $E(n)_{2 n+4}$. The theorem stated in the introduction now follows.

Added in proof. By substituting $u v$ for $y$ in $(\mathrm{C})$ and linearizing, one obtains $(u, v, x, z, z, z) \equiv 1 \bmod \langle u, v, x, z\rangle_{7}$, which shortens some of the arguments given above.

$\bar{I}$. D. Ivanjuta [Certain groups of exponent four, Dopovidi Akad. Nauk Ukrain RSR Ser. A (1969), 787-790)] has shown that every $n$ generator group of exponent 4 satisfying $(x, y, y, y)=1$ identically has class at most $2 n$. His methods are specific to such groups, however, and do not apply readily to $B(n)$ or $E(n)$.

\section{REFERENCES}

1. N. D. Gupta and K. W. Weston, On groups of exponent four, J. Algebra, 17 (1971), 59-65.

2. C. K. Gupta and N. D. Gupta, On groups of exponent four II, Proc. Amer. Math. Soc., 31 (1972), 360-362.

3. N. D. Gupta and R. B. Quintana, Jr., On groups of exponent four III, Proc. Amer. Math. Soc., 33 (1972), 15-19.

4. C. R. B. Wright, On the nilpotency class of a group of exponent four, Pacific J. Math., 11 (19ô1), 387-394.

Received October 1, 1971 and in revised form January 10, 1972. The second author is indebted to the National Science Foundation for contract support of his work on this paper.

UNiversity of Wisconsin, PARKSIDE

AND

UNIVERSITY OF OREGON 



\section{PACIFIC JOURNAL OF MATHEMATICS}

\section{EDITORS}

\section{H. SAMELSON}

Stanford University

Stanford, California 94305

C. R. Новву

University of Washington Seattle, Washington 98105

\section{J. DuGundJI}

Department of Mathematics University of Southern California Los Angeles, California 90007

RICHARD ARENS

University of California Los Angeles, California 90024

\section{ASSOCIATE EDITORS}
E. F. BECKENBACH
B. H. NeumanN
F. WOLF
K. YoSHIDA

\section{SUPPORTING INSTITUTIONS}

\author{
UNIVERSITY OF BRITISH COLUMBIA \\ CALIFORNIA INSTITUTE OF TECHNOLOGY \\ UNIVERSITY OF CALIFORNIA \\ MONTANA STATE UNIVERSITY \\ UNIVERSITY OF NEVADA \\ NEW MEXICO STATE UNIVERSITY \\ OREGON STATE UNIVERSITY \\ UNIVERSITY OF OREGON \\ OSAKA UNIVERSITY
}

\author{
UNIVERSITY OF SOUTHERN CALIFORNIA \\ STANFORD UNIVERSITY \\ UNIVERSITY OF TOKYO \\ UNIVERSITY OF UTAH \\ WASHINGTON STATE UNIVERSITY \\ UNIVERSITY OF WASHINGTON \\ $*{ }^{*}$
AMERICAN MATHEMATICAL SOCIETY
NAVAL WEAPONS CENTER
}

The Supporting Institutions listed above contribute to the cost of publication of this Journal, but they are not owners or publishers and have no responsibility for its content or policies.

Mathematical papers intended for publication in the Pacific Journal of Mathematics should be in typed form or offset-reproduced, (not dittoed), double spaced with large margins. Underline Greek letters in red, German in green, and script in blue. The first paragraph or two must be capable of being used separately as a synopsis of the entire paper. The editorial "we" must not be used in the synopsis, and items of the bibliography should not be cited there unless absolutely necessary, in which case they must be identified by author and Journal, rather than by item number. Manuscripts, in duplicate if possible, may be sent to any one of the four editors. Please classify according to the scheme of Math. Rev. Index to Vol, 39. All other communications to the editors should be addressed to the managing editor, Richard Arens, University of California, Los Angeles, California, 90024.

50 reprints are provided free for each article; additional copies may be obtained at cost in multiples of 50 .

The Pacific Journal of Mathematics is issued monthly as of January 1966. Regular subscription rate: $\$ 48.00$ a year (6 Vols., 12 issues). Special rate: $\$ 24.00$ a year to individual members of supporting institutions.

Subscriptions, orders for back numbers, and changes of address should be sent to Pacific Journal of Mathematics, 103 Highland Boulevard, Berkeley, California, 94708.

PUBLISHED BY PACIFIC JOURNAL OF MATHEMATICS, A NON-PROFIT CORPORATION

Printed at Kokusai Bunken Insatsusha (International Academic Printing Co., Ltd.), 270, 3-chome Totsuka-cho, Shinjuku-ku, Tokyo 160, Japan. 


\section{Pacific Journal of Mathematics}

\section{Vol. 44, No. $2 \quad$ June, 1973}

Tsuyoshi Andô, Closed range theorems for convex sets and linear liftings . . . . . . 393

Richard David Bourgin, Conically bounded sets in Banach spaces . . . . . . . . . 411

Robert Jay Buck, Hausdorff dimensions for compact sets in $R^{n} \ldots \ldots \ldots \ldots \ldots \ldots . \ldots 421$

Henry Cheng, A constructive Riemann mapping theorem ................ 435

David Fleming Dawson, Summability of subsequences and stretchings of

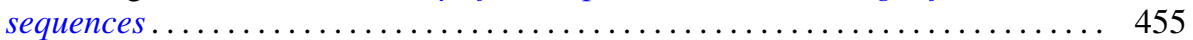

William Thomas Eaton, A two sided approximation theorem for 2-spheres ....... 461

Jay Paul Fillmore and John Herman Scheuneman, Fundamental groups of compact complete locally affine complex surfaces ....................... 487

Avner Friedman, Bounded entire solutions of elliptic equations . . . . . . . . . . . 497

Ronald Francis Gariepy, Multiplicity and the area of an $(n-1)$ continuous

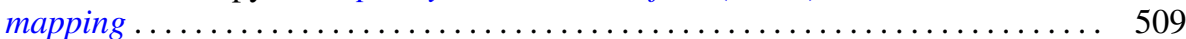

Andrew M. W. Glass, Archimedean extensions of directed interpolation groups . . . . 515

Morisuke Hasumi, Extreme points and unicity of extremum problems in $H^{1}$ on

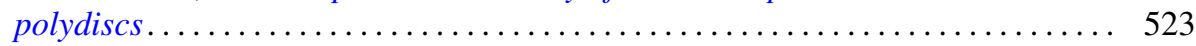

Trevor Ongley Hawkes, On the Fitting length of a soluble linear group . . . . . . 537

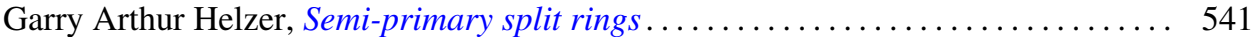

Melvin Hochster, Expanded radical ideals and semiregular ideals . . . . . . . . . 553

Keizō Kikuchi, Starlike and convex mappings in several complex variables . . . . . . 569

Charles Philip Lanski, On the relationship of a ring and the subring generated by its

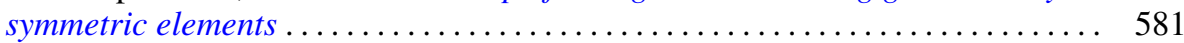

Jimmie Don Lawson, Intrinsic topologies in topological lattices and semilattices ........................................... 593

Roy Bruce Levow, Counterexamples to conjectures of Ryser and de Oliveira ...... 603

Arthur Larry Lieberman, Some representations of the automorphism group of an infinite continuous homogeneous measure algebra ..........

William George McArthur, $G_{\delta}$-diagonals and metrization theorems $\ldots .$.

James Murdoch McPherson, Wild arcs in three-space. II. An invariant of

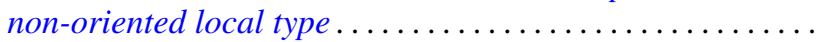

H. Millington and Maurice Sion, Inverse systems of group-valued measures ...

C. Edward Moore, Concrete semispaces and lexicographic separation of convex

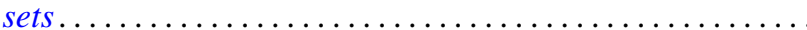

Jingyal Pak, Actions of torus $T^{n}$ on $(n+1)$-manifolds $M^{n+1}$.

Merrell Lee Patrick, Extensions of inequalities of the Laguerre and Turán type . . . . 675

Harold L. Peterson, Jr., Discontinuous characters and subgroups of finite index. . . . 683

S. P. Philipp, Abel summability of conjugate integrals . . . . . . . . . . . . . 693

R. B. Quintana and Charles R. B. Wright, On groups of exponent four satisfying an

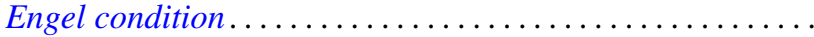

Marlon C. Rayburn, On Hausdorff compactifications. . . . . . . . . .

Martin G. Ribe, Necessary convexity conditions for the Hahn-Banach theorem in

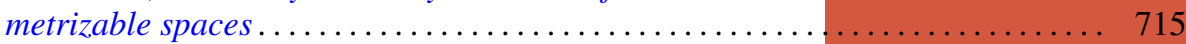

Ryōtarō Satō, On decomposition of transformations in infinite measure spaces .... 733

Peter Drummond Taylor, Subgradients of a convex function obtained from a

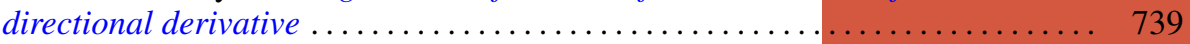

James William Thomas, A bifurcation theorem for $k$-set contractions . . . . . . . . 749 Clifford Edward Weil, A topological lemma and applications to real functions . . . . 757

Stephen Andrew Williams, A nonlinear elliptic boundary value problem . . ....... 767

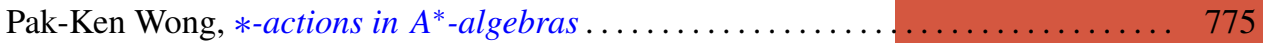

